\title{
The Cause of Mechanical Vibration of Palasher Synchronous Motors and its Removal
}

\author{
Jiř́ Pavelka ${ }^{1)}$, Josef Šimek, Pavel Kobrle ${ }^{1)}$ and Petr Kokeš ${ }^{2)}$ \\ 1) Czech Technical University in Prague, Faculty of Electrical Engineering, Department of Electric Drives and Traction, \\ Prague, Czech Republic, e-mail: \{pavelka,kobrlpav\}@fel.cvut.cz \\ 2) The Czech Academy of Sciences, Institute of Thermomechanics, Department D 6 - Electrical Engineering and \\ Electrophysics, Prague, Czech Republic, e-mail: kokes@it.cas.cz
}

\begin{abstract}
The paper describes the procedure and the result of the analysis of mechanical vibrations of mining machines at the Palasher mine in the Russian Federation. The cause of these vibrations was the change in the magnitude of the magnetic flux in the air gap. The simulations showed the possibility of eliminating these changes in magnetic flux by injecting suitable voltages into the stator windings. The implementation of this injection is further described by torque variable component feed-direct compensation. Finally, oscillography records are presented before and after injection.
\end{abstract}

Keywords - mining machine, synchronous machine, indirect frequency converter, Maxwell's force, resonant frequency, feedforward compensation, voltage injection.

\section{INTRODUCTION}

The Czech company ELEKTROTECHNIKA, a. s., (earlier CKD Elektrotechnika, a. s.) is, besides other things, a long-term supplier of electric drives for high power hoisting (mining) machines. These are controlled drives with specific requirements for their design, implementation and control. The development of power electronics converters made it possible to replace the original supply of DC mining motors from rotating Ward Leonard sets with the supply from thyristor rectifiers and later to replace the DC motors with the synchronous motors supplied from high-voltage frequency converters with the voltage DC-links.

A hoist tower with an electric drive is a complex mechanical system whose natural vibration frequencies are dependent on its stiffness. These frequencies may be close to the resonant frequency occurring at some operating speed or at some speed during the start up or breaking when the machine remains there for a longer time. It may cause the unacceptable vibration of the hoist tower. [1] describes in detail the problem of mechanical oscillation of a $4 \mathrm{MW}$ DC motor supplied from a thyristor rectifier. The paper contains an analysis of possible causes of this vibration and also the description of the implemented method leading to reducing the vibrations to the permissible limit.

This article is the English version of the Czech article [6]. It contains the description of the mechanical vibrations of the mining machines that are driven by the slow running synchronous motors $5 \mathrm{~T} 404-40 \mathrm{H} 1800 \mathrm{~kW}$, $6000 \mathrm{~V}$, speed $58 \mathrm{rpm}$, and $5 \mathrm{~T} 448-40 \mathrm{H} 5800 \mathrm{~kW}, 6000 \mathrm{~V}$, speed $51 \mathrm{rpm}$ in the mine Palasher in Russia. It also contains an analysis of the causes of the vibration, a proposal of the method of its elimination, the results of simulation verification, and the results of the implementation of the proposed method on real drives in Palasher.

\section{THE BASIC PARAMETERS OF THE DRIVES IN THE PALASHER MINE}

The Czech company ELEKTROTECHNIKA, a. s., supplied one electric drive for 1.8 MW hoisting machine and two electric drives for 5.8 MW hoisting machines in the Palasher mine in the Russian Federation to the company INCO Engineering, spol. s r.o.

The basic parameters of the $1.8 \mathrm{MW}$ drive for the hoisting machine are the following:

- Slow running synchronous motor 5T404-40H $1800 \mathrm{~kW}, \quad 6000 \mathrm{~V}, 186 \mathrm{~A}$, speed $58 \mathrm{rpm}$, $\cos \varphi=1$ from the company ČKD Kompresory, a. s. (now Howden ČKD Compressors, s. r. o.);

- Multilevel frequency converter $6 \mathrm{kV} / 6 \mathrm{kV}$, $50 \mathrm{~Hz} / 19.33 \mathrm{~Hz}$ from the company ČKD Elektrotechnika, a. s. (now ELEKTROTECHNIKA, a. s.);

- Control system EMADYN F from the company ČKD Elektrotechnika, a. s. that uses the system of the company Beckhoff for the superior control.

After the production at the end of 2013, the complete drive was tested in no-load operation in the test room of the company ČKD Kompresory, a. s. Already during the tests, the engine vibrated excessively when passing some speed.

Due to the fact that the motor was fastened to the temporary foundation of the test room and its rotor was on spare bearings, the solution of the problem of mechanical vibration was postponed until commissioning in the customer's mine. At the beginning of April 2016, speed tests of the drive were carried out in the Palasher mine. During the speed tests, the motor was assembled with traction wheels of the hoisting machine, but without ropes and has not yet concreted its foundation. During the acceleration and deceleration, the mining machine passed through two bands of mechanical resonance.

The basic parameters of the 5.8 MW drives for the hoisting machine are the following:

Slow running synchronous motor $5 \mathrm{~T} 448-40 \mathrm{H}$ $5800 \mathrm{~kW}, 6000 \mathrm{~V}, 585 \mathrm{~A}$, speed $51 \mathrm{rpm}$, $\cos \varphi=1$ from the company ČKD Kompresory, a. s. (now Howden ČKD Compressors, s. r. o.);

Multilevel frequency converter $6 \mathrm{kV} / 6 \mathrm{kV}$, $50 \mathrm{~Hz} / 17 \mathrm{~Hz}$ from the company ČKD 
Elektrotechnika, a.s. (now ELEKTROTECHNIKA, a. s.);

- Control system EMADYN F from the company ČKD Elektrotechnika, a. s. that uses the system of the company Beckhoff for the superior control.

Production of complete drives, their no-load tests in the testing room of the production company ČKD Kompresory, a. s. and commissioning in the Palasher mine took place only a few months after the commissioning of 1.8 MW drive, and the similar vibrations of the hoisting machines were found as well.

In April 2016, the technical director of ČKD Elektrotechnika, a. s. asked the authors of the paper [1] for the preparation of an analysis of the causes of this mechanical vibration, the determination of the drive component causing it and the submission of any proposal for how to eliminate the mechanical vibration. The authors of the paper [1] prepared such an analysis in the form of a technical report based on the received technical background and data and they submitted it in May 2016 as [2]. The proposed measure was elaborated in detail, supplemented and implemented by Ing. Kokeš from the Czech Academy of Sciences. At present, the drives of all hoisting machines are in full operation.

\section{THE HYPOTHESIS OF THE CAUSE OF MECHANICAL VIBRATION}

The following paragraphs give a physical explanation of how the excitation force causing the vibration is originated.

Fig. 1 shows the oscillogram of 1.8 MW synchronous motor rundown from the rated speed to zero without being supplied from the frequency converter.

It is apparent from the record that mechanical vibration occurs at $9.28 \mathrm{rpm}$, i.e. $16 \%$ of the nominal speed, and $18.54 \mathrm{rpm}$, i.e. $32 \%$ of the nominal speed, during the rundown of the excited synchronous motor and when the stator current is zero. This eliminates the effect of the frequency converter that supplies the stator winding on this vibration. Another test showed that the vibration does not occur when the synchronous motor is not excited during the rundown. This implies that the cause of the vibration is the mechanical forces that occur in the air gap of the rotating excited rotor of the synchronous motor.

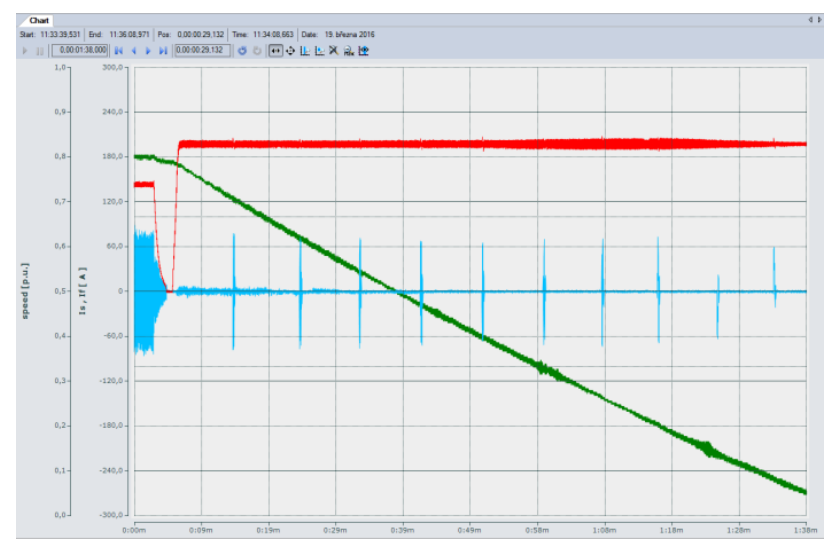

Fig. 1. Recorded oscillogram of the rundown of 1.8 MW excited motor; speed (green), stator current (blue), excitation current (red).

\section{A. Lorentz's and Maxwell's Power in the Air Gap}

It is known from the theory of electrical machines that two forces are created in the air gap of any type of rotary electric machine:

a) Lorentz's force $F_{\mathrm{L}}$, which acts on an electric conductor of length $L$ moving at velocity $v$ in a magnetic field $B$. The sum of all these forces creates an electromagnetic torque $T_{\mathrm{e}}$ on the circumference of the air gap.

For a salient poles synchronous motor with an excitation winding:

$$
T_{\mathrm{e}}=\mathrm{k}_{\mathrm{M}} \cdot \hat{\Phi} \cdot \hat{I}_{\mathrm{a}}=\mathrm{k}_{\mathrm{M}} \cdot \hat{B}_{\delta} \cdot S \cdot \hat{I}_{\mathrm{a}}
$$

where $\mathrm{k}_{\mathrm{M}}$ is the constant of the motor, $\hat{\Phi}$ represents the space vector of the magnetic flux, $\hat{I}_{\mathrm{a}}$ is the space vector of the stator current, $\hat{B}_{\delta}$ is the space vector of the magnetic field in the air gap and $S$ is the area through which passes the field lines of the magnetic field.

b) Maxwell's attractive $F_{\mathrm{M}}$ force, which acts in the air gap between the pole extensions of the stator and rotor. The following can be written for it:

$$
F_{\mathrm{M}}=\frac{1}{2 \mu} B_{\delta}^{2} S,
$$

where $\mu$ is the permeability of the air.

It can be seen from the record in Fig. 1 that the oscillation occurs even at zero stator current $I_{\mathrm{a}}$ and therefore the Lorentz's force can be unequivocally eliminated as the cause of the vibration. But what is the magnitude of Maxwell's attractive force in the air gap?

In salient poles synchronous motor with an excitation winding, the excitation (field) current controller determines its magnitude so that the magnetic field in the air gap $B_{\delta}$ is constant. The following applies:

$$
B_{\delta}=\frac{f_{\phi}\left(I_{\mathrm{f}}\right)}{R_{\mathrm{m}}},
$$

where $f_{\phi}\left(I_{\mathrm{f}}\right)$ is the magnetomotive force of the excitation winding of one pole and $R_{\mathrm{m}}$ is the magnetic reluctance of the magnetic circuit of one pole.

Maxwell's force of one pole to the stator $F_{\mathrm{M}}$ is obtained by substituting (3) to (2). This power is always attractive.

In a synchronous motor with equally large air gaps between the poles and the stator bore surface, the forces of the opposite pole extensions are identical, the direction of their action is opposite in space, and therefore their sum is theoretically zero.

In fact, however, the position of the rotor axis relative to the stator has always a certain eccentricity, which is the result of inaccurate positioning of the rotor in the center of the stator bore and deflection of the rotor due to its weight. This eccentricity causes the force $\Delta F_{\mathrm{M}}$, which acts between the stator and the rotor in the direction of this eccentricity.

\section{B. Influence of the Air Gap Size Variation on Force in the Eccentricity Axis}

Both 1.8 MW and 5.8 MW motors have the same number of stator slots $N_{\mathrm{d}}=240$ and their rotors have the 
same number of poles $2 p=40$. Then the number of slots per pole $N_{\mathrm{p}}$ is:

$$
\left.N_{\mathrm{p}}=\frac{N_{\mathrm{d}}}{2 p}=\frac{240}{40}=6 \text { (slots } / \text { pole }\right) .
$$

The stator of $1.8 \mathrm{MW}$ synchronous motor has the bore $D_{\mathrm{vr}}=2860 \mathrm{~mm}$. The stator slot span $\tau_{\mathrm{d}}$ is:

$$
\tau_{\mathrm{d}}=\frac{\pi D_{\mathrm{vr}}}{N_{\mathrm{d}}}=\frac{\pi \cdot 2860}{240}=\frac{8985}{240}=37.44(\mathrm{~mm}) .
$$

The stator slot width is $b_{\mathrm{d}}=18.4 \mathrm{~mm}$ and the slots are open. The ratio $b_{\mathrm{d}} / \tau_{\mathrm{d}}=18.4 / 37.44=0.49$ is therefore normal. The width of the pole extension $b_{\mathrm{pn}}$ is $165 \mathrm{~mm}$. Thus, under one pole extension there is a total of $N_{\mathrm{pn}}$ slots:

$$
N_{\mathrm{pn}}=\frac{b_{\mathrm{pn}}}{\tau_{\mathrm{d}}}=\frac{165}{37.44}=4.4 \text { (slots } / \text { pole ext.) }
$$

Thus, when the rotor is rotating, the number of slots under the pole extension varies between four slots and five slots. This results in a periodic change of the magnetic reluctance $R_{\mathrm{m} \delta}$ in the air gap due to the stator slotting, which is replaced by the sinusoidal waveform according to (7):

$$
R_{\mathrm{m} \delta}=R_{\mathrm{m} \delta 0}\left(1+\mathrm{k}_{\mathrm{m} \delta} \sin \left(2 \pi f_{\mathrm{dr}} t\right)\right),
$$

where $\mathrm{k}_{\mathrm{m} \delta}$ is the coefficient of the air gap varying due to the stator slotting and $f_{\mathrm{dr}}$ is the slotting frequency.

At a constant magnetomotive force of the no-load excitation current $F_{0}$, the fluctuation of the magnetic flux in the air gap $\Phi_{\delta}$ will be described by:

$$
\begin{aligned}
\Phi_{\delta} & =\frac{F_{0}}{R_{\mathrm{m} \delta 0}\left(1+\mathrm{k}_{\mathrm{m} \delta} \sin \left(2 \pi f_{\mathrm{dr}} t\right)\right)} \cong \\
& \cong \Phi_{\delta 0}\left(1-\mathrm{k}_{\mathrm{m} \delta} \sin \left(2 \pi f_{\mathrm{dr}} t\right)\right)
\end{aligned} .
$$

Substituting into (2) we get

$$
\begin{aligned}
F_{\mathrm{M}} & =\frac{1}{2 \mu} B_{\delta}^{2} S=\frac{\Phi_{\delta}^{2}}{2 \mu S}=\frac{\Phi_{\delta 0}^{2}}{2 \mu S}\left(1-\mathrm{k}_{\mathrm{m} \delta} \sin \left(2 \pi f_{\mathrm{dr}} t\right)\right)^{2}= \\
& =\frac{\Phi_{\delta 0}^{2}}{2 \mu S}\left(\begin{array}{l}
1-2 \cdot 1 \cdot \mathrm{k}_{\mathrm{m} \delta} \sin \left(2 \pi f_{\mathrm{dr}} t\right)+ \\
+\mathrm{k}_{\mathrm{m} \delta}^{2} \sin ^{2}\left(2 \pi f_{\mathrm{dr}} t\right)
\end{array}\right) \approx \\
& \approx F_{\mathrm{Mpn} 0}\left(1-2 \mathrm{k}_{\mathrm{m} \delta} \sin \omega_{\mathrm{dr}} t\right)
\end{aligned}
$$

\section{Determining the Frequency of the Forced Magnetic Flux Variation}

The change in magnetic reluctance is caused by changing the number of slots under the pole extension. In one revolution, this change occurs $N_{\mathrm{d}}$ times. Both types of motors have the same number of stator slots and the number of poles. Therefore, the relation between the supply frequency $f_{\mathrm{s}}$ and the excitation frequency since the change of the magnetic flux $f_{\mathrm{dr}}$ in both motors is the same:

$$
f_{\mathrm{dr}}=\frac{N_{\mathrm{d}}}{p} f_{\mathrm{s}}=\frac{240}{20} f_{\mathrm{s}}=12 f_{\mathrm{s}} .
$$

For the operation of the hoist machine, it is important, that the mechanical resonance does not occur at the speed at which the drive rotates for a longer time, or that the hoist machine or some of its parts must not inadmissibly vibrate when passing through the resonant zone during the start up or breaking.

\section{Possibilities to Eliminate the CAUSE OF THE \\ EXCITATION FORCE OF MECHANICAL VIBRATIONS}

The actual cause of the excitation force is therefore the slotting on the internal diameter of the stator of the synchronous motor. Medium and large low-voltage electric rotary machines and all high-voltage electric rotary machines have in the stator open slots because of technological reasons, that concern the manufacturing of the winding. This causes a relatively large change in the magnetic reluctance of the air gap. Therefore, it is important that its magnitude, and especially the frequency, do not adversely affect the function of the entire mechanical system. It is known from the mechanics that every complex mechanical system has its resonant frequencies.

This results in the following options for reducing or eliminating the cause of the excitation force:

1. To select the fractional number of stator slots per pole per phase when designing the motor. As a result, the slot frequency and the excitation force frequency are shifted to a higher value outside the resonant frequencies of the mechanical system. However, this cannot be done on an already manufactured machine.

2. To tune the mechanical system of the hoisting machine so that its resonant frequencies are beyond the excitation frequencies. While there are many known methods for tuning the system to other resonant frequencies, they are usually hard to do on an already completed system.

3. To use magnetic slot wedges to close the stator slots of the synchronous motor. These considerably reduce the magnetic unevenness of the air gap and thereby also substantially reduce the magnitude of the excitation force due to fluctuations of the magnetic reluctance in the air gap. Replacing the magnetic slot wedges on the already manufactured machine is also usually difficult to perform.

4. To inject AC voltages of appropriate frequency, amplitude and phase into the excitation or stator windings so that the generated currents counteract the change in magnetic flux in the air gap, thereby reducing or eliminating this change. This fourth option has been used and will be described in more detail in the following text.

\section{A. Method of Injection of AC Voltage Component}

Let's use a simplified model of the generation of the excitation force. The effects of the individual windings in the longitudinal axis of the synchronous motor can be described on the basis of the notion of magnetic fluxes and their paths according to Fig. 2. Similarly, assuming zero magnetic flux in the transverse axis $\Psi_{\text {sq }}$, it is possible to draw an equivalent diagram of the electrical circuits and their interconnections for the longitudinal axis of the synchronous motor (Fig. 3).

According to the equivalent diagram in Fig. 3, four equations can be written in which there are six variables: 
$u_{\mathrm{sd}}, i_{\mathrm{sd}}, i_{\mathrm{m}}, i_{\mathrm{D}}, u_{\mathrm{f}}, i_{\mathrm{f}}$. For an unambiguous solution, two variables must be chosen as independent variables.



Fig. 2. Equivalent diagram of the magnetic circuits in the d-axis (indices: $\mathrm{s}$ - stator, D - damper, $\mathrm{f}-$ excitation (field), $\sigma$ - leakage, $\mathrm{m}$ - main)

Usually, it is $u_{\mathrm{sd}}$ and $u_{\mathrm{f}}$. Similarly, according to the equivalent diagram in Fig. 2, six equations can be written in which there are eight variables: $u_{\mathrm{sd}}, i_{\mathrm{sd}}, \Psi_{\mathrm{sd}}, i_{\mathrm{D}}, \Psi_{\mathrm{D}}, u_{\mathrm{f}}, i_{\mathrm{f}}$, $\Psi_{\mathrm{f}}$. For an unambiguous solution, two variables must be chosen as independent variables. Usually, it is $u_{\mathrm{sd}}$ and $u_{\mathrm{f}}$ again. In mathematical models of electric machines, it is commonly assumed that the parameters $R_{\mathrm{s}}, R_{\mathrm{D}}, R_{\mathrm{f}}, L_{\mathrm{m}}, L_{\sigma \mathrm{S}}$, $L_{\sigma \mathrm{D}}, L_{\sigma \mathrm{\sigma}}$ are constants. In this case, however, the main magnetic flux $\Psi_{\mathrm{m}}$ periodically changes due to the variable air gap, and it results in the time varying magnetizing inductance $L_{\mathrm{m}}$. This can be described by the following equation:

$$
L_{\mathrm{m}}=L_{\mathrm{m} 0}+\Delta L_{\mathrm{m}} \sin \left(2 \pi f_{\mathrm{dr}} t\right) .
$$

If the main magnetic flux $\Psi_{\mathrm{m}}$ is to be constant, its derivative must be zero:

$$
\begin{aligned}
\frac{\mathrm{d} \Psi_{\mathrm{m}}(t)}{\mathrm{d} t} & =\frac{\mathrm{d}}{\mathrm{d} t}\left(L_{\mathrm{m}}(t) \cdot i_{\mathrm{m}}(t)\right)= \\
& =\frac{\mathrm{d} L_{\mathrm{m}}(t)}{\mathrm{d} t} i_{\mathrm{m}}(t)+L_{\mathrm{m}}(t) \frac{\mathrm{d} i_{\mathrm{m}}(t)}{\mathrm{d} t}=0
\end{aligned}
$$

\section{B. Simulation of the Injection}

The equivalent scheme in Fig. 3 and the derived equations were programmed in MATLAB-Simulink. Simulation calculations were made on this model to inject a suitable compensating voltage into both the excitation winding and the stator winding.

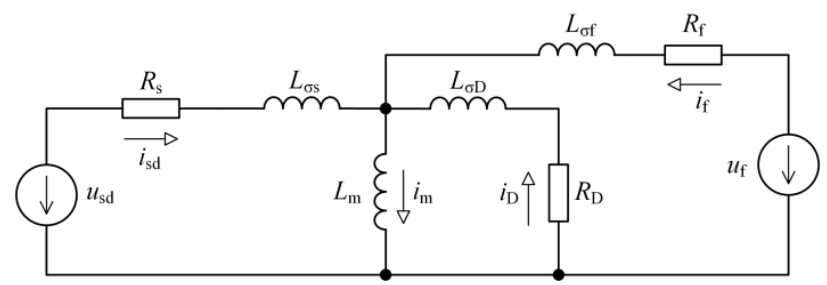

Fig. 3. Equivalent diagram of the electric circuits in the d-axis
These calculations confirmed the possibility of suppressing magnetic flux variations due to slotting. While the required magnitude of the injected voltage into the excitation winding determined by simulation has an unrealizable tenfold value of the nominal excitation voltage, the value of the injected voltage into the stator winding has a real magnitude of less than a tenth of the nominal stator voltage. A more detailed description and results are presented in [5].

\section{Realization of the Injection on Drives in Palasher}

Ing. Kokeš from the Czech Academy of Sciences developed three methods of voltage injection into the stator winding:

1. To add the basic vector regulation of the magnetic flux and the machine torque with a resonant controller of the stator current.

2. To add a resonant element to PI speed control.

3. To add the feedforward compensation of the alternating torque component using a mathematical model of the synchronous machine winding.

The undesired alternating torque component was compensated by adding the compensating signal $T_{e 12 C}^{*}$ at the torque regulator input in Fig. 4. $\mathrm{R}$ is the resonant element, which together with the PI controller in the superior system forms the PIR speed controller. At the output of $\mathrm{R}$ is the compensating torque $T_{e 12 C}^{*}$, which is added to the required torque value $T_{e M}^{*}$ from the superior controller. The required value for control by the part $\mathrm{R}$ is zero. Therefore, the output $T_{e 12 C}^{*}$ of controller $\mathrm{R}$ suppresses the unwanted component $12 \omega_{\mathrm{r}}$ (twelvefold of the rotational speed). The part $\mathrm{R}$ is continuously tuned to a resonant frequency of $12 \omega_{\mathrm{r}}$ according to the measured actual speed $\omega_{\mathrm{r}}$, which is filtered by the low pass filter LPF, so that tuning $\mathrm{R}$ is not negatively affected by component 12.

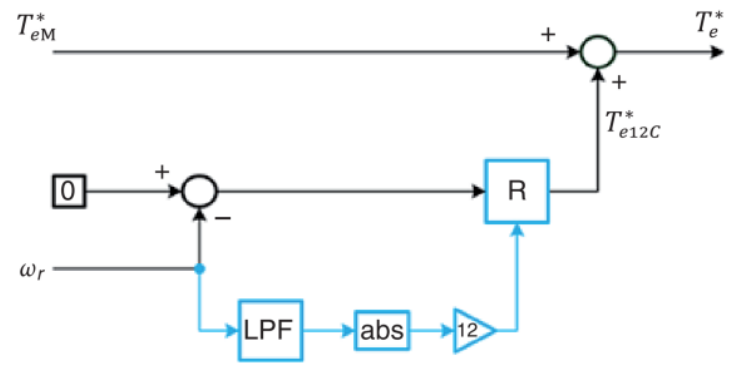

Fig. 4. Compensation of unwanted AC torque component using the resonant speed controller

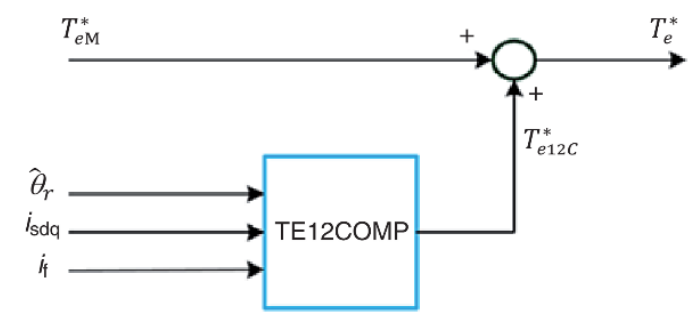

Fig. 5. Feedforward compensation of the AC torque component 


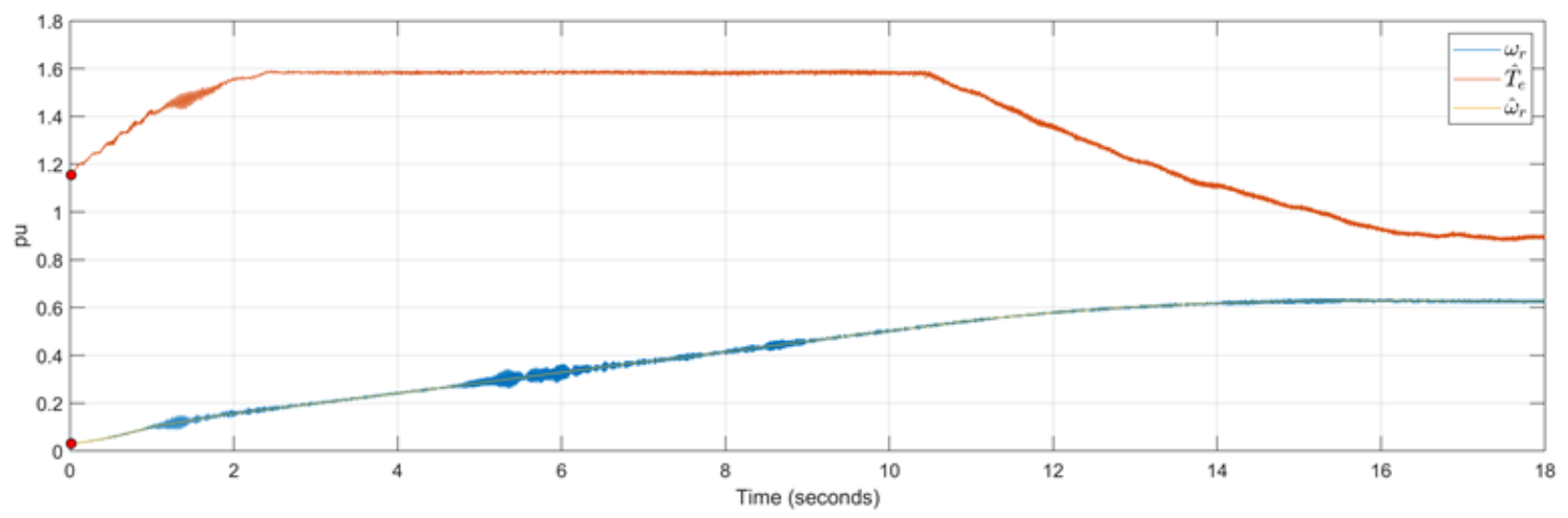

Fig. 6. The speed (blue) and torque $T_{\mathrm{e}}^{*}$ (red) during run up of the drive $5.8 \mathrm{MW}$ with maximal torque - without compensation

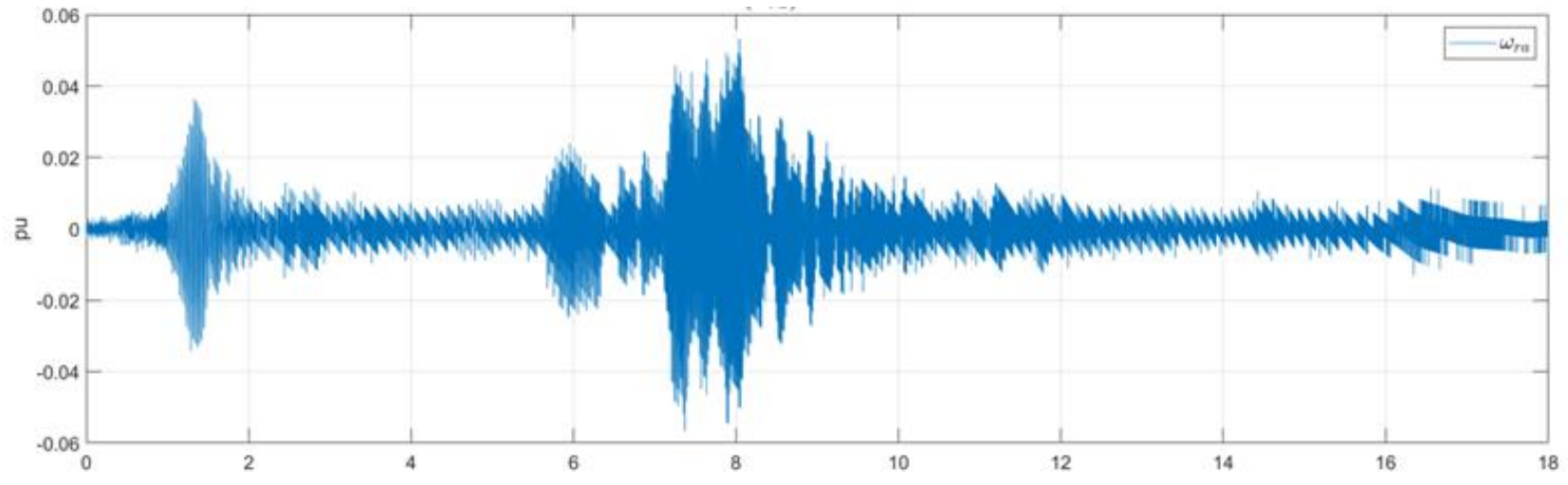

Fig. 9. AC component of the instantaneous speed during run up of the 5.8 MW drive with maximal torque - without compensation

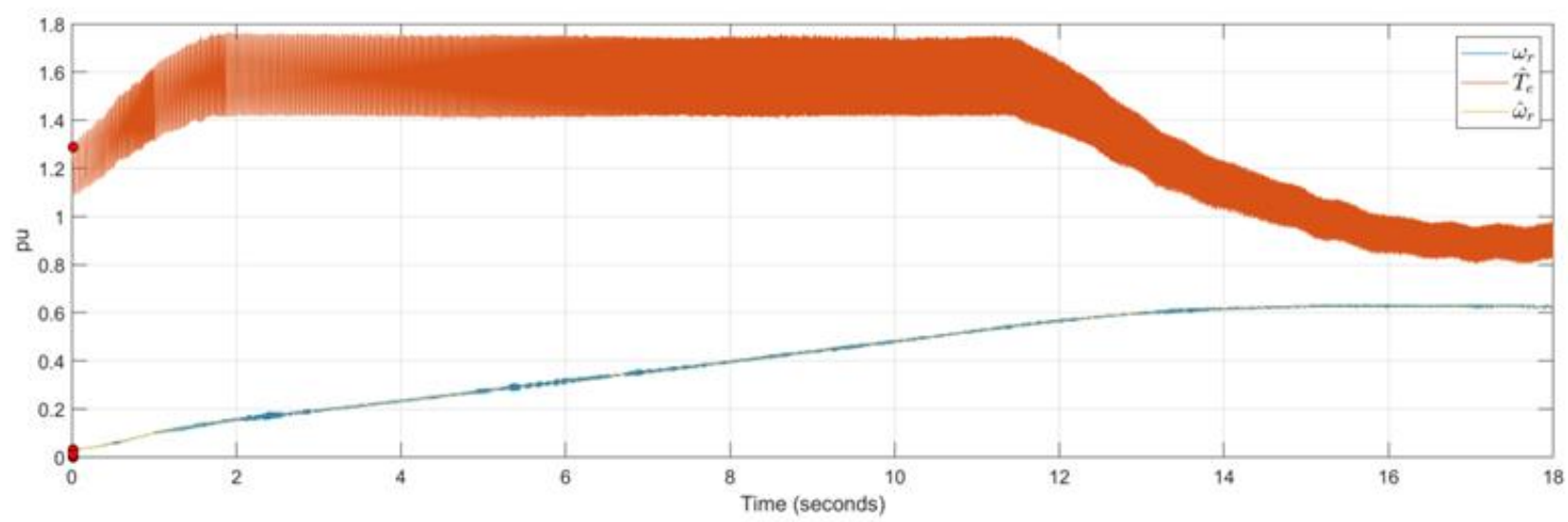

Fig. 8. The speed (blue) and torque $T_{\mathrm{e}}^{*}$ (red) during run up of the drive $5.8 \mathrm{MW}$ with maximal torque - with feedforward compensation 


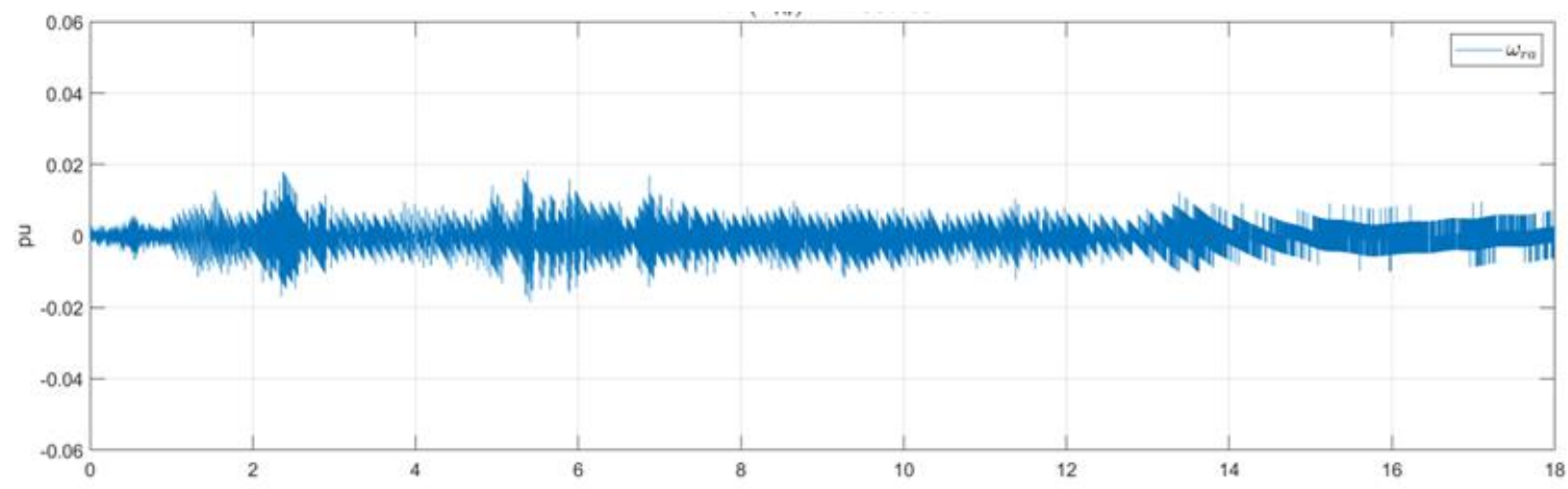

Fig. 9. AC component of the instantaneous speed during run up of the 5.8 MW drive with maximal torque - with feedforward compensation

Each resonant controller is very sensitive to the transport delay of the controlled variable. Therefore, this controller worked stably only at very low speeds up to $0.025 \omega_{\mathrm{rn}}$. The signal quality of the measured velocity $\omega_{\mathrm{r}}$ deteriorates with increasing value due to vibration disturbances. Another disadvantage is the relatively long stabilization of the control at higher speed changes, which can reach several tens of seconds. With the help of the resonant velocity controller, it was only possible to remove the vibrations from the ropes at very low speeds, and it was necessary to look for another method that would work satisfactorily in the entire speed range $\omega_{\mathrm{r}}$.

This showed method number 3. Method number 2 was used only in the auxiliary measurements, in which the parameters of each synchronous machine needed for the third method were obtained. All three methods are described in more detail in [5].

The basis of the feedforward compensation is the direct calculation of the torque component $T_{e 12 C}^{*}$ from the instantaneous values of the stator current components $i_{\mathrm{sd}}$, $i_{\text {sq }}$, excitation current $i_{\mathrm{f}}$ and the rotor position angle $\theta_{\mathrm{r}}$ in the mathematical model of the machine, which was created using so called winding functions [3]. Such a model makes it possible to respect the spatial arrangement of the slots and the winding wires. The most general model requires knowledge of twelve parameters. Some of them may be zero. Detailed measurements on all machines showed that for each machine, it is appropriate to use a different number of non-zero parameters in the TE12COMP model in Fig. 5. The calculated $T_{e 12 C}^{*}$ component is added to the torque value $T_{e M}^{*}$ from the torque controller to the resulting torque $T_{e}^{*}$ as in Fig. 4 in the resonant controller.

The result of the use of the feedforward compensation is shown in the recorded oscillograms of the instantaneous speed $\omega_{\mathrm{r}}$ and the required torque $T_{e}^{*}$. Fig. 6 shows the run up of the $5.8 \mathrm{MW}$ motor without compensation and Fig. 7 shows only the AC component of the instantaneous speed. Fig. 8 and Fig. 9 show the same situation with feedforward compensation. From their comparison, it is evident that the compensation significantly reduced the resonance bands of the vibration in the speed, and at the required torque an $\mathrm{AC}$ component with an amplitude of $0.15 T_{\text {en }}$ appeared.

\section{CONCLUSION}

The paper shows how the modern control and computer technology make it possible to solve a problem which has appeared during the drive commissioning after it was manufactured and assembled. Further, it demonstrates how the theoretical knowledge of electrical machines is important for the creation of the necessary mathematical model. It also shows how important it is to follow the recommendations for the electromagnetic design of electric machines, in this case the recommended number of slots per pole per phase of slow running machines.

\section{REFERENCES}

[1] J. Pavelka, P. Pavelka, and J. Šimek, "Kmitání těžního stroje na dole Kirovsk," (in Czech), $34^{\text {th }}$ Conference on Electric Drives (ELPO), Pilsen, June 2015, pp. 44-49.

[2] J. Pavelka, J. Šimek, P. Kobrle, "Posudek a analýza příčin mechanického rozkmitání synchronního motoru 1,8 MW, $6 \mathrm{kV}$ na zakázce Malý Palašer," (in Czech), unpublished.

[3] P. Krause, O. Wasynczuk, S. Sudhoff, S. Pekarek, Analysis of Electric Machinery and Drive Systems, $3^{\text {rd }}$ ed., John Wiley\&Sons, Inc., Hoboken, New Jersey, 2013. https://doi.org/10.1002/9781118524336

[4] A.H. Toliyat, N.A. Al-Nuaim, "Simulation and Detection of Dynamic Air-Gap Eccentricity in Salient-Pole Synchronous Machines," IEEE Trans. Ind. App., vol. 35, pp. 86-93, January/February 1999. DOI: $10.1109 / 28.740849$ https://doi.org/10.1109/28.740849

[5] J. Pavelka, J. Šimek, P. Kobrle and P. Kokeš, "Příčina mechanického chvění těžních synchronních motorů Palašer a jeho odstranění," (in Czech), 36 $6^{\text {th }}$ Conference on Electric Drives (ELPO), Pilsen, June 2019, pp. 1-21.

[6] J. Pavelka, J. Šimek, P. Kobrle, P. Kokeš, "Příčina mechanického chvění těžních synchronních motorů Palašer a jeho odstranění," (in Czech), Elektro, vol. 11, November 2019, pp. 6-9. 